Distribution Category:

Magnetic Fusion Energy

(UC-420)

\title{
ALIFPP/TI-248
}

ALL/FPP/TH--248

DE90 013634

ARCOUNE MATIOWAL LABORATORY

9700 South Cass Avenue

Argonne, Illinois 60439-4801

SIMUATIOAs OF ICDF-FAST UAVE cunnatr DAIVE an DIIID

by

David A. Ehst

Fusion Power Program/Engineering Physics

June 1990

Hork supported by

Orfice of Fusion Energy

U.S. Departwent of Energy

under Contract $1-31-109-$ Eng-38 
rour or consurs

Page

abstract $\quad \ldots \ldots \ldots \ldots \ldots \ldots \ldots \ldots \ldots \ldots \ldots \ldots \ldots \ldots \ldots \ldots \ldots \ldots \ldots \ldots \ldots \ldots \ldots \ldots . \ldots \ldots$

1. Introduction $\ldots \ldots \ldots \ldots \ldots \ldots \ldots \ldots \ldots \ldots \ldots \ldots \ldots \ldots \ldots \ldots \ldots \ldots \ldots \ldots$

2. Experinental Conditions $\ldots \ldots \ldots \ldots \ldots \ldots \ldots \ldots \ldots \ldots \ldots \ldots \ldots \ldots \ldots \ldots \ldots . \ldots$

3. Example Calculation $\ldots \ldots \ldots \ldots \ldots \ldots \ldots \ldots \ldots \ldots \ldots \ldots \ldots \ldots \ldots \ldots \ldots . \ldots$

4. Survey Results $\ldots \ldots \ldots \ldots \ldots \ldots \ldots \ldots \ldots \ldots \ldots \ldots \ldots \ldots \ldots \ldots \ldots \ldots \ldots \ldots \ldots . \ldots$

5. Typical Profiles - Two Exaples $\ldots \ldots \ldots \ldots \ldots \ldots \ldots \ldots \ldots \ldots \ldots \ldots \ldots \ldots$ 7

6. Conclustons $\ldots \ldots \ldots \ldots \ldots \ldots \ldots \ldots \ldots \ldots \ldots \ldots \ldots \ldots \ldots \ldots \ldots \ldots \ldots \ldots \ldots . . \ldots$

References $\quad \ldots \ldots \ldots \ldots \ldots \ldots \ldots \ldots \ldots \ldots \ldots \ldots \ldots \ldots \ldots \ldots \ldots \ldots \ldots \ldots \ldots \ldots \ldots \ldots . . \ldots$ 


\section{LIST a pigunas}

Pase

Figure 1 Typical ray trajectories in DIIID.

Figure 2 Evolution of index of refraction, $n n_{n}$, normalized parallel phase velocity, $\omega=\omega / k_{1} y_{e}$, and normalized current drive efficiency [9] with and without electron trapping, plotted along a ray trajectory. ....

Figure 3 For the save ray as in Fig. 2, power density left In the wave and the flux-surface averaged paraliel current density generated.

Figure 4 For case 53, the self-consistent MHD equilibriu showing: a) the flux-surface-averaged bootstrap current density (chain-dot), the wave driven seed current near the magnetic axis (PSIHAT $=1.0$ ), and the total current density (dotted), vs. normalized poloidal flux; b) the resulting toroidal current density profile in the aidplane; c) the safety factor.

Figure 5 Single pass absorption vs. $n_{1}$. Top curve: $T_{e 0}=$ $6.5 \mathrm{keV}, \mathrm{B}_{0}=1.0 \mathrm{~T}, \mathrm{~B}_{t}=1.0 \mathrm{~T}, \mathrm{~B}_{t}=2.2 \%$. Hiddle curve: $T_{e o}=3.5 \mathrm{keV}, B_{0}=1.0 \mathrm{~T}, B_{t}=1.27$. Botton curve: $T_{e O}=6.5 \mathrm{keV}, \mathrm{B}_{\mathrm{o}}=1.9 \mathrm{~T}, \mathrm{~B}_{\mathrm{t}}=0.74 . \ldots$

Figure 6 Single pass absorption vs. beta. Points clustered around upper curve have $n_{l}=5.0$; open circles are $n_{1}=2.5$. Results include both $T_{e 0}=6.5 \mathrm{keV}$ and $3.5 \mathrm{keV}$ and $\mathrm{B}_{\mathrm{O}}=1.0 \mathrm{~T}$ and $1.9 \mathrm{~T}$. 
Figure 7 Influence of $P_{\text {edge }}$ on: a) ${ }_{\text {edge }}^{B}$ and b) axis safety factor. Dotted curves are low beta $(=0.73)$ with $T_{e}=1.5 \mathrm{kel}$ and $2.2 \mathrm{keV}$. Solid curves are higher beta ( $=1.4-2.93)$ with $\mathrm{T}_{e}=1.5 \mathrm{keV}$ and $2.8 \mathrm{keV}$. $\ldots \ldots$.

Flgure 8 Total current vs. a) $\mathrm{I}_{e}$ and b) pressure; all with $2_{\text {erf }}=2.2$. Pentagons have $T_{e o}=6.5 \mathrm{keV}, \mathrm{n}_{e 0}=$ $0.18 \times 10^{20} \mathrm{~m}^{-3}, B_{0}=1.0 \mathrm{~T}$, various $n_{1}$; open circles have $T_{e 0}=6.5 \mathrm{keV}, n_{e o}=0.30 \times 10^{20} \mathrm{~m}^{-3}$, $B_{0}=1.9 T$, various $n_{1}$; triangles have $T_{e o}=$ $3.5 \mathrm{keV}, \mathrm{n}_{\mathrm{eo}}=0.30 \times 10^{20} \mathrm{~m}-\mathrm{B}_{\mathrm{o}}=1.0 \mathrm{~T}$, different $n_{\mathbf{l}}$.

Figure 9 Current vs. average density. Top curve: $\mathbb{T}_{e}=$ $1.7 \mathrm{keV}, z_{\text {eff }}=4.0, B_{t} \leq 0.7 \%, P_{\text {edge }}=1.80 \mathrm{~km}$. Botton curve: $\mathrm{T}_{e} \approx 0.8 \mathrm{keV}, \mathrm{z}_{\text {efr }}=2.2, \mathrm{~B}_{t} \geq$ $0.75, P_{\text {edge }}=1.10 \mathrm{~ms}$.

Figure 10 Efficiency vs. $Z_{\text {eff }}$. Top curve: $T_{e o}=6.5 \mathrm{keV}$; triangles $-B_{t}=1.4 \%$, circles $-B_{t}=0.7 \%$. Botton curve: $T_{\text {eo }}=3.5 \mathrm{keV}, B_{t}=0.7 \%$.

Figure 11 Teaperature profile (dashed) obtained from FuCD calculation $\left(t_{e}=0.69 \mathrm{keV}, \mathrm{n}_{e 0}=0.20 \times 10^{20} \mathrm{~m}^{-3}\right.$, $\bar{n}_{e}=0.13 \times 10^{20} \mathrm{~m}^{-3}, \mathrm{~B}_{\mathrm{o}}=1 \mathrm{~T}, 2=4.0, \mathrm{P}_{\text {edge }}=$ $\left.1.80 \mathrm{~m}, I_{0}=176 \mathrm{kA}\right)$; and teaperature profile (solid) measured in DIIID [12].

Figure 12 Calculated toroidal current density in midplane (a) with FUCD (296 kA); experimental current density (b) from MBCD [11] (340 kA).

\section{LIST OF TARLES}




\section{ABstact}

Self-consistent calculations of MHD equilibria, generated by fast wave current drive and including the bootstrap effect, were done to guide and anticipate the results of upconing experiments on the DIIID tokanak. The simulations predict that $2 \mathrm{MH}$ of ICRF power is more than adequate to create several hundred kiloawperes in steady state; the total current increases with the temperature and density of the target plasma.

\section{Inrroosuction}

According to theory [1-3], the fast wave polarization promises superior tokamak current drive performance at high plasia temperature and density, compared to the slow (lower hybrid) wave. A nuber of experimental tests have been carried out [4] to test fast wave current driva (FicD), but these experiments have concentrated on wave frequencies at high harmonics of the fundanental deuteriun cyclotron frequency $\left(u \geq 10 a_{D}\right)$. Recently, direct electron heating via transit-tine-magnetic-puming (TMM) was deconstrated on JET [5] with a nondirectional antenna at frequencies ("ICRF") near the fundanental, bolstering the belief that FUCD is possible at the ICRF. The DIIID tokanak will provide the first opportunity to test this concepi with a directional antenna.

As an aid to designing and interpreting the DIIID experiments a number of calculations of FWCD were done with the RIP code, [6] which self-consistently calculates 2-D tokanak equilibria with bootstrap and fast wave seed currents, and these results are presented here. Three modifications to RIP were instituted to accurately model low frequency Fico:

1. The effect of TMM on wave danping and FKCD $[3,7]$ was added to the code. There is a transition from Landau daping to IMAP as the 
frequency drops and the electron temperature increases [8], which is accounted for in the calculations.

2. Electron agnetic trapping at sall aspect ratios can severely reduce FUCD, so care was taken to appropriately nodel this neoclassical erfect [9].

3. Signifleant wodiflcations to the bootstrap transport coefficients were found (10) when finite aspect ratio was properly factored into the neoclassical theory, and these updated coefficients are used in our work.

As will becone apparent, the bootstrap current plays an important role under the DIIID conditions postulated in our calculations.

\section{Expenirgiral compitions}

The assuned DIIID geometry is:

$$
\begin{aligned}
\mathbf{R}_{\mathbf{0}}=1.67 \mathbf{n} & & \text { (major radius) } \\
\mathbf{a}=0.56 & & \text { (midplane minor radius) } \\
\mathbf{x}=1.6 & & \text { (elongation) } \\
\mathbf{d}=0.25 & & \text { (triangularity) }
\end{aligned}
$$

Have propagation and danping is assumed in a pure deuterium plasma at a wave frequency of $60 \mathrm{MHz}$. Two values of the magnetic field on the magnetic axis are considered $-\mathrm{B}_{0}=1.0 \mathrm{~T}$ and $1.9 \mathrm{~T}-$ - corresponding respectively to FuCD at the eighth and fourth cyclotron harmonics.

For simplicity the antenna spectru is modelled by a single toroidal index of refraction, $n_{1}$, and with a poloidal wode number $k_{\theta} \equiv 0$. The antenna launches power from the outboard midplane, and the total antenna radiation incident on the plasma is 1 imited to $P_{\text {edge }} \leq 2.0 \mathrm{~m}$. In RIP, typically five rays are launched over a poloidally distributed antenna extent ( $\pm 0.21 \mathrm{~m}$, above and below the nidplane) with symetric power distribution to nodel the Input power. 
In the calculatiors we assume that a range of central electron densities $-0.18 \leq\left[n_{e o} / 10^{20} m^{-3}\right) \leq 0.40 \ldots$ should be attainable in DIIID [11,12]. It is essential to achieve a hot electron plasia to desonstrate FWCD, and we thus assume that additional heating (ECRI or neutral beans) will combine with the ICRF to provide a peak temperature in the range $3.5 \mathrm{keV} \leq \mathrm{T}_{\text {eo }}$ $\leq 6.5 \mathrm{keV}[12]$. Pressure and temperature profiles influence the spatial distribution of the absorbed power and hence the resulting current density profile. We consider a variety of profiles in an attempt both to compare with previous experimental measurements and to study profile effects on FWCD. In the RIP calculation of the HHD equilibrium and ray tracing/FucD the pressure is defined as $p(\bar{\psi})=p_{0} \bar{\psi}^{\alpha}$, where $\bar{\psi}$ is the normalized poloidal flux; and the pressure width is varied over $1.4 \leq a \leq 3.0$. The temperature and density are given by $T_{e}(\tilde{\psi})=T_{e o} \tilde{\psi}^{T}$ and $n_{e}(\tilde{\psi})=n_{e o} \tilde{\psi}_{n}$, and their volune average values, $T_{e}$ and $\bar{n}_{e}$ are varied by adjusting the exponents such that $a_{T}+a_{n}=a$. An additional uncertainty will be the impurity level during FicD. Higher $\bar{n}_{e}$

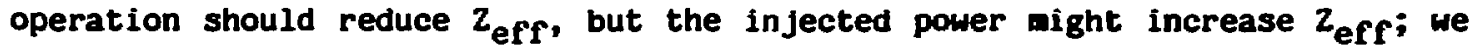
examine two values -- $z_{\text {eff }}=2.2$ and 4.0 in this note.

An important caveat to our conclusions is that our calculations assune a true steady state with zero electric field. This will apply to the experiment only after the loop voltage vanishes and when the internal inductance becomes constant (perhaps several hundred ailliseconds after applying the ICRF power [11]).

\section{ERAPLe calculatios}

The RIP code iterates between calculations of the miD equilibrium and solutions to the ray-tracing and current gerseration problew until the system converges to consistency. Figure 1 displays the ray trajectories of a typical example (Case 58 in Table I), and Fig. 2 illustrates the inportant parameters along the path of ray 13 (launched on the widplane with $n_{1}=5.0$ ). From Fig. 1 it is seen that the ray passes close to the magnetic axis before bending outward. (A11 calculations are stopped before the rays are reflected; thus any power not absorbed in a single pass through the plasina is assumed to be lost.) The abscissa in Fig. 2 is the nomalized flux $(\tilde{\psi}=0.0$ is the boundary; $\tilde{\psi}=1.0$ is the magnetic axis), and the paraneters are plotted for the inward-bound portion of the trajectory. 
The Index of refraction, $n_{1}$. Increases by a factor of two, due to the andl aspect ratio of DIIID, as the ray approaches the axis. A crucial variable, the ratio of parallel phase speed to the electron thermal speed -$\omega \mp\left(c / v_{e} n_{1}\right)$, arfects both the dasping strength and the current drive efficiency. Due to the variation of $n_{1}$ and $T_{e}$ along the ray path, $w$ decreases from large values to near $w=1.0$. When $w \gg 1$ the (nomalized) efficiency or current drive is large; this efriciency, $\tilde{n}$, is shom in the figure as a solid 11ne. Wote that in a straight magnetic field (no trapped electrons) the efficiency $\bar{\eta}(c=0)$ would be substantially larger. The dominant effect on FiCD, however, is that wave daping is extrenely weak when $w \geq 3$ so that very little power density is absorbed for $\bar{\psi} \leq 0.5$. This is 1llustratict in FiB. 3 , where the ray's power is seen to dininish strongly near the axis. The generated

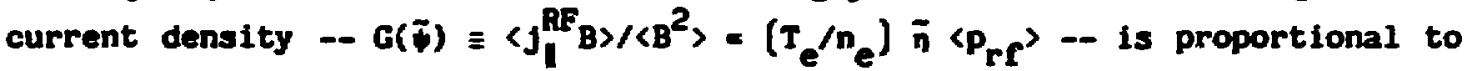
the dissipated wave power $\left\langle p_{\mathbf{r f}}\right\rangle$ and peaks strongly near the axis.

The contributions to $G(\tilde{\psi})$ from all five rays are sumed and simoothed, and the bootstrap current, $H(\tilde{\psi})=\left\langle j_{1}^{B T} B\right\rangle\left\langle B^{2}\right\rangle$, is also calculated. Figure 4 (from Case 53) shows that the bootstrap current typically supplies the bulk of the total current density. It is noteworthy in the fixture that even though $G+H=$ 0 at the plasia boundary the dianagnetic (Prirsch-Schluter) current contributes to the toroidal component of the equilibriu current density.

We study the sensitivity of the expected DIIID results to:

a. the antenna paraneters

$n_{1}$
Pedge

b. the plasma parameters

$T_{e o}$ and $\mathbf{T}_{e}$

$n_{e o}$ and $\bar{n}_{e}$

Bo (which deternines beta)

zerf 
The principal functions which we wonitor include the fractional power

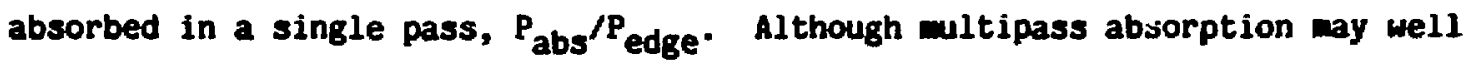
happen in FUCD experiments we are wore confident of success in DIIID if $P_{a b s} / P_{\text {edge }}$ is large $(\geq 0.5)$. We also calculate total current, $I_{0}$, the plasina profiles, and the rigure of merit for FicD, $\gamma_{\text {edge }}^{B}=\bar{n}_{e} I_{o} R_{o} / P_{e d g e}$, these quantities being measurable from the experimental diagnostics. (The superscript "B" rewinds us that bootstrap currents contribute to $I_{0}$, although the siaple MHD diagnostic loops cannot differentiate between the bootstrap and fast-wave components of $I_{0}$. The subscript "edge" indicates that only $P_{\text {edge }}$ is known in the experiment since the absorbed $r f$ power is not readily inferred. If multipass absorbtion indeed occurs, then $Y_{\text {edge }}^{B}$ would be larger than the values quoted here.

Further, we calculate both the "Troyon ratio" and the axis safety factor, $q_{a x i s}$, of the resulting equilibria. The Troyon ratio is defined as

$$
B_{T}=B_{t} a B_{0} / I_{0}
$$

where $\theta_{t}$ is the toroidal beta; a conservative estimate would expect that $\boldsymbol{B}_{T}$ cannot exceed -3.0 , although DIIID has done wuch better. Likewise, conservative planning might avold $q_{a x i s} \leq 1.0$ which could lead to instability. A final constraint in this work was to livit our results to converged equilibria with essentially wonotonic safety factors $q(\tilde{b})$ (which is easily achieved by supplying sufficient $P_{\text {edge }}$ to drive adequate seed current near the magnetic axis -- see Fig. 4).

\section{SURVEY RESULTS}

Power absorption vs. ny (Fig. 5)

As expected from Fig. 2 , selecting $n_{y} \geq 5$ at the antenna results in $w=2$ and strong damping when $T_{e o}=6.5 \mathrm{keV}$. Moreover, as shown in Fig. 5 , selecting faster waves with $n_{1} \leq 3$ results in weaker absorption on the first pass. Nevertheless, at high $B_{t}$ (top curve) over $50 \%$ of the power is absorbed in a single pass even for rather low $n_{1}$. Importantly, the normalized efficiency, $\gamma_{\text {edge }}^{B}$ is found in these calculations to be almost independent of $n_{1}$, due to the large bootstrap current contribution to the equilibria. Thus, for a given antenna power the steady state current is insensitive to the n, launched (provided the spectrum is directional, of course). 
Power absorption us. beta (Fig. 6)

The most important factor to guarantee strong absorption is to increase beta. As the figure shows, $P_{\text {abs }} / P_{\text {edge }} \geq 50 \%$ provided $B_{t} \geq 1.0 \%$, regardless of $n_{\mathbf{l}}$.

\section{Sensitivity to $P_{\text {odgo }}$ (Fig. 7 )}

Due to the large bootstrap current, the effective current drive efficiency, $\gamma_{B}^{B}$ edge, is not a simple monotonic function of $T_{e}$. In fact, Fig. $7 a$ shows that $Y_{B}$ edge increases as $P_{\text {edge }}$ decreases. The curves in Fig. $7 a$ vary as $r_{\text {edge }}^{B}=P_{\text {adge' }}^{-1}$ which produces the interesting result that $I_{0}\left(=r_{\text {edge }}^{B} P_{\text {edge }}\right)$ is Independent of the antenna power over the range plotted. The lower limit to Pedge would occur when so little power is available to generate a seed current that the safety factor is non-monotonic ( $q_{\text {axis }}$ is too large). As seen in Fig. $7 b$, at high values of $P_{\text {edge }}$ the axis safety factor is depressed; so for the high beta cases (solid curve) an upper linit of $\mathrm{P}_{\text {edge }}=0.6 \mathrm{~m}$ aight be operable if instability occurs for $q_{\text {axis }} \leq 1$.

\section{Current vs. average electron teaperature (Fig. 8)}

Although $I_{0}$ is insensitive to $n_{1}$ and $P_{\text {edge, }}$ it depends strongly on the average electron temperature. The points in Fig. 8 were obtained by varying the widths of the temperature and density profiles for given peak values. Thus, the pentagons, all with $T_{e o}=6.5 \mathrm{keV}$, show $I_{0}$ increasing as $\mathrm{T}_{e}$ varies from $0.5 \mathrm{keV}$ to $3.0 \mathrm{keV}$. This underscores the relative importance of achieving high average temperatures (rather than high peak tesperatures). For example, off-axis ECRH combined with central fast wave heating could be considered as a means of broadening the temperature profile and raising $I_{0}$.

While single pass absorption was dependent on beta, it is significant that Io does not increase with beta. For exasple, the open circles in the figure correspond to $I_{0}$ as $h i_{g h}$ as $480 \mathrm{kA}$, but they all have $c_{t} \leq 0.8 \%$; the pentagons at the same high $I_{0}$ range all have $B_{t} \geq 2.0 \%$. Since the highest beta cases graphed have Troyon ratios $\mathrm{B}_{\mathrm{T}} \approx 3.5$ there way be a tendancy for these discharges to exhibit instability. Hence the (lower beta) experiments at $B_{0}=1.9 \mathrm{~T}$ way generate just as much current but will be in safer operating regines with respect to $\mathrm{q}_{\text {axis }}$ and $\mathrm{B}_{\mathrm{T}}$.

Figure $8 \mathrm{~b}$ provides an alternative plot, of $I_{0}$ vs. the plasma pressure. It is difficult to conclude whether $I_{0}$ scales with electron temperature or with pressure. 


\section{Current vs. density (Fis. 9)}

Figure 9 shows that $I_{0}$ increases with density, due to the strong bootstrap component. (This trend would not be true in the absence of the bootstrap effect, since elementary current drive theory would predict $I_{0}<\bar{n}_{e}^{-1}$ at constant $P_{\text {edge }}$ ] Wote that the upper curve (with $\tau_{e}=1.7 \mathrm{keV}$ ) represents larger current at a fixed density, even though beta is lower and $z_{\text {eff }}$ is higher than in the lower curve (with $\mathrm{T}_{e}=0.8 \mathrm{keV}$ ). The better fast wave coupling at high density and the large bootstrap contribution are strong motivations to pursue FWCD on DIIID at rather high $\tilde{\mathbf{n}}_{e}$.

\section{Efficiency vs. 2off (Fig. 10)}

At a fixed density and temperature the effective current generation erficiency decreases as the inpurity content increases, as shown in Fig. 10. The points on a straight line in the figure represent about constant current. As $Z_{\text {eff }}$ increases the required $P_{\text {edge }}$ increases, but even at $Z_{\text {eff }}=$ 4.0 there is ample power in DIIID to generate several hundred kiloameres.

\section{TYPICAE FROFILOS - THO EXMTLES}

The dashed curve in Fig. 11 is the temperature profile across the midplane for Case 59. This steady state equilibrium was calculated for an assumed temperature profile $T_{e}=T_{e o} \tau^{1.7}$ and corresponds to a total current $I_{0}=176 \mathrm{kA}$ and $\theta_{\mathrm{t}}=0.67$ at $B_{0}=1.0 \mathrm{~T}$. The solid curve, for comparison, is the measured temperature profile in Ref. [12], obtained with -1 of ECRH at the same density as for the FWCD calculation $-\bar{n}_{e}=0.13 \times 10^{20} \mathrm{~m}^{-3}$. The congruence of the curves encourages us that the $T_{e}$ profiles assuned in our calculations are typical of what my be achieved in the actual FucD experiment.

It is interesting to compare FWCD predictions with the actual experience with neutral beam current drive (NBCD) on DIIID. Figure 12 shows the toroidal current density in the aidplane for Case $58-296 \mathrm{kA}$ at $\bar{n}_{e}=0.13 \times 10^{20} \mathrm{~m}^{-3}$, $T_{\text {eo }}=6.5 \mathrm{keV}$, and $B_{0}=1.0 \mathrm{~T}$, with $B_{t}=1.4 \%$. The current density is qualitatively sinilar to the inferred profile (Rer. 11) in the MBCD experiment which achieved $340 \mathrm{kh}$ at $\bar{n}_{e}=0.20 \times 90^{20} \mathrm{~m}^{-3}, \mathrm{~T}_{\text {eO }} \leq \mathrm{T}_{\mathrm{io}}=2.0 \mathrm{keV}$, and $\mathrm{B}_{\mathrm{O}}=$ $2.1 \mathrm{~T}$, with $B_{t}=0.5 \%$. A shifted magnetic axis and an inboard region of 
reversed toroidal current density occur in both cases. The MBCD experiment used $10 \mathrm{~m}$ of injected power, while the FuCD example requires only $1 \mathrm{~kW}$ of power. The higher FuCD efficiency arises primarily due to the larger bootstrap contribution -- at $T_{e 0}=6.5 \mathrm{keV}$ and $\bar{n}_{e}=0.13 \times 10^{20} \mathrm{~m}^{-3}$ the effective collisionality, vy, is further into the banama regime than for the MBCD experinent.

\section{6. concuusions}

Regarding the multi-loop antenna:

- The FWCD results are insensitive to $n_{1}$, so any value, $n_{1}-2-8$, will drive current, provided the power spectrun is directional.

- The available ICRE power, $P_{\text {edge }} \leq 2.0 \mathrm{~m}$, is adequate to provide several hundred kiloasperes. Owing to the bootstrap effect, the total equilibrium current is essentially independent of Pedge. [at too low a power the safety factor may become double-valued, and at too high a power $q_{a}$ ma be driven below unity, depending on the value of $B_{0} \cdot J$

A successful experiment depends mostly on a well-prepared target plasia:

- The wave power absorbed in a single pass through the plasma increases with beta, and for the assumed conditions in DIIID we generally find $\mathrm{P}_{\text {abs }} / \mathrm{P}_{\text {edge }} \geq 50 \%$; witipass absorption would inprove upon the results cited in this report.

- The resulting current appears to increase with electron pressure, so the average $\mathrm{T}_{e}$ should be maxinized by raising the central $\mathrm{T}_{e 0}$ and especially by broadening the temperature profile (by off-axis ECRH, for example).

- Likewise, Io increases with electron density. (Antenna coupling should also improve with density.) Experiments with $\bar{n}_{e} \geq 0.2 \times$ $10^{20} \mathrm{~m}^{-3}$ will be most successful and will be wost weaningriul with respect to future tokamaks such as ITER. For the best results, 
sufficient heating power is needed to provide $T_{e} \geq 2$ kel as the density is increased.

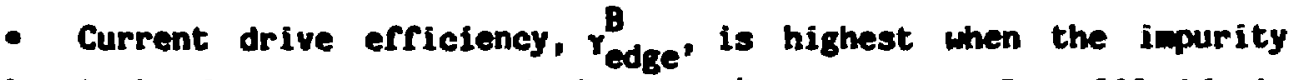
level is low, but even at $z_{\text {erf }}-4$ we expect $I_{0} \geq 200 \mathrm{kA}$ is achievable with the avallable pour.

In sumary, DIIID should serve as an excellent test of the FuCD concept. The min challenges w11l be to provide good antenna-plasina coupling with a directional spectrum and a hot electron target plasina for the waves.

\section{References}

1. D.R. Ehst, in Non-inductive current drive in tokaraks, Proc. IAEA Tech. Com. Mtg., Culhan 1983, Culhan Laboratory Report CLM-CD (1983), D.F.H. Start, ed., vol. ii, p. 442.

2. F.W. Perkins, in FED-A, Oak Ridge lational Laboratory Report OAUL/FEDC83/1 (1983), Y-K.K. Peng and P.H. Rutherford, eds., p. 4-28.

3. D. Moreau, J. Jacquinot, P.P. Lallia, "Fast Wue Current Drive," in JET Contributions to 13th European Conf. Contr. Fusion and Plase Heating (Schliersee 1986), JET Report JET-P(86) 15, P. 65.

4. D.A. Ehst, WFast Wave Current Drive: Experimental Status and Reactor Prospects," Argonne lational Laboratory Report ML/FPP/MH-219 (1988).

5. L.-G. Ericksson and T. Hellsten, Mucl. Fusion 29 ( 1989) 875.

6. H.-Y. Hsiao, D.A. Ehst, K. Evans, Jr., Mucl. Fusion 29 (1989) 49.

7. H.J. Fisch, C.F.F. Karney, Phys. Fluids 24 (1981) 27.

8. S.C. Chiu, Y.S. Chan, R.H. Harvey, H. Porkolab, lucl. Fusion 29 (1989) 2175. 
9. D.A. Enst, C.F.F. Karney, Wooclassical Erfocts on RF Current Drive," Arconne Mational Laboratory Report Mu/FPP/Th-247 (1990).

10. S.P. Hirshan, Phys. Fluids 31 (1988) 3150.

11. T.C. Simonen et al., Phys. Rev. Lett. 61 (1988) 1720.

12. R. Prater at al., "Electron Cyclotron Heating Experiments in the DIII-D Tokank," in Plasm Physics and Contr. Huclear Fusion Res. 1988, Proc. 12th Conf., Mice 1988, vol. 1, p. 527. 


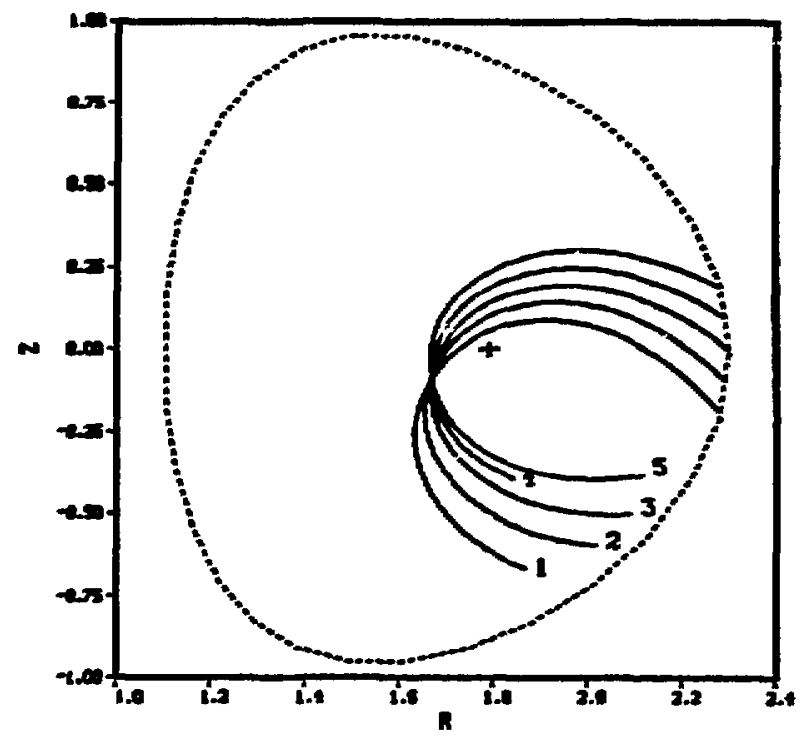

Figure 1. Typical ray trajectorles in DIIID.

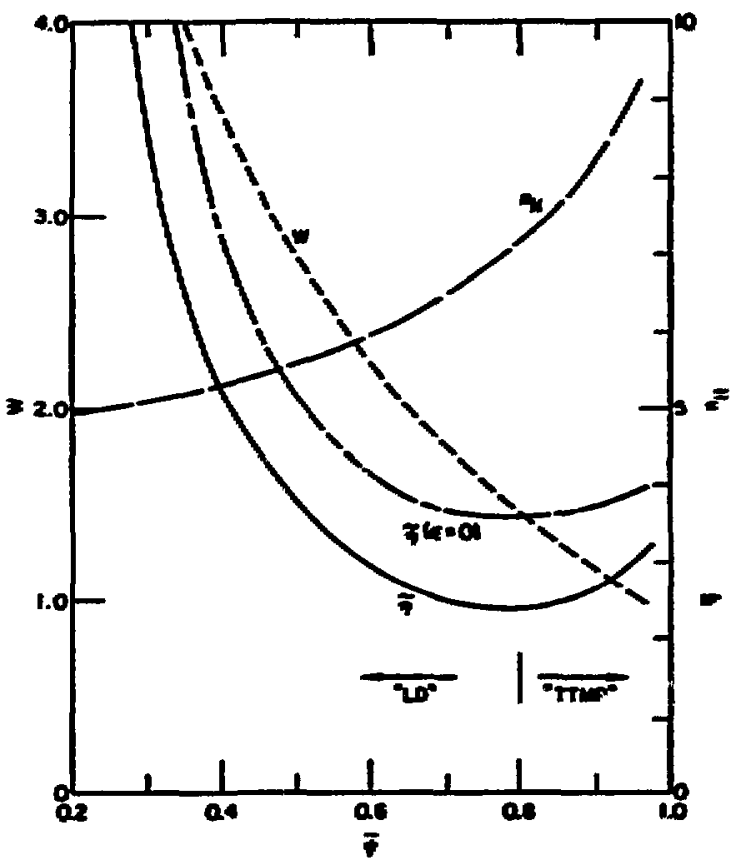

Figure 2. Evolution of index of refraction, $n_{n}$, normalized parallel phase velocity, $\omega=\omega / k_{1} y^{\prime}$, and normelized current drive efficiency [9] with and without electron trapping, plotted alons a ray trajectory. 


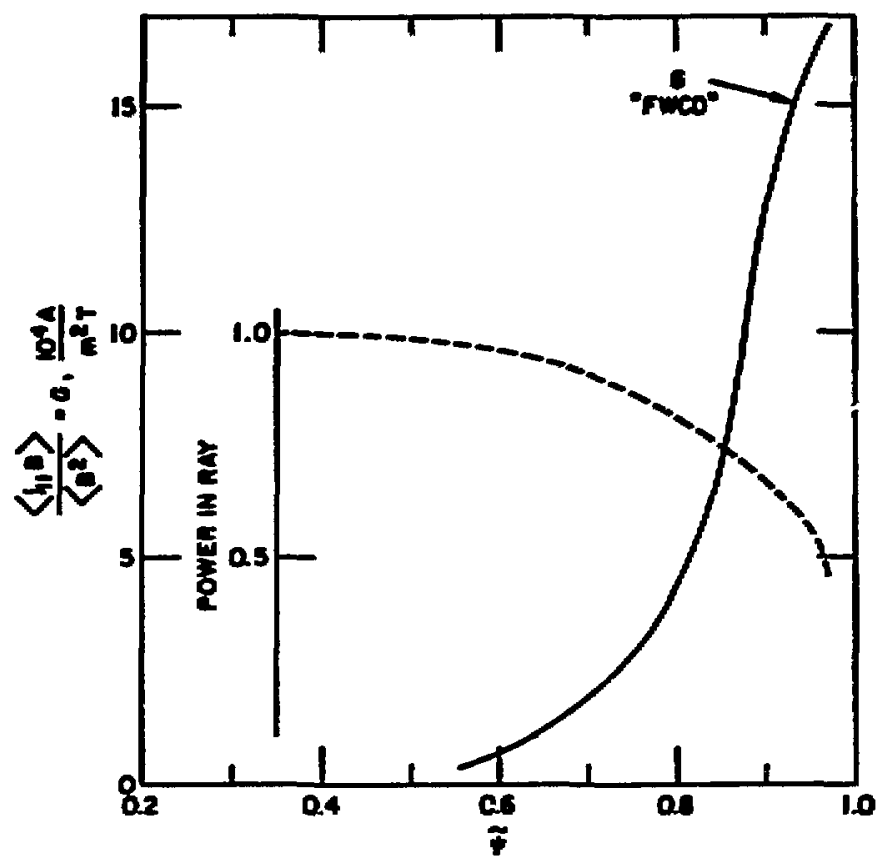

Figure 3. For the sane ray as in Fig. 2, power density left in the wave and the flux-surface averaged parallel current density generated.
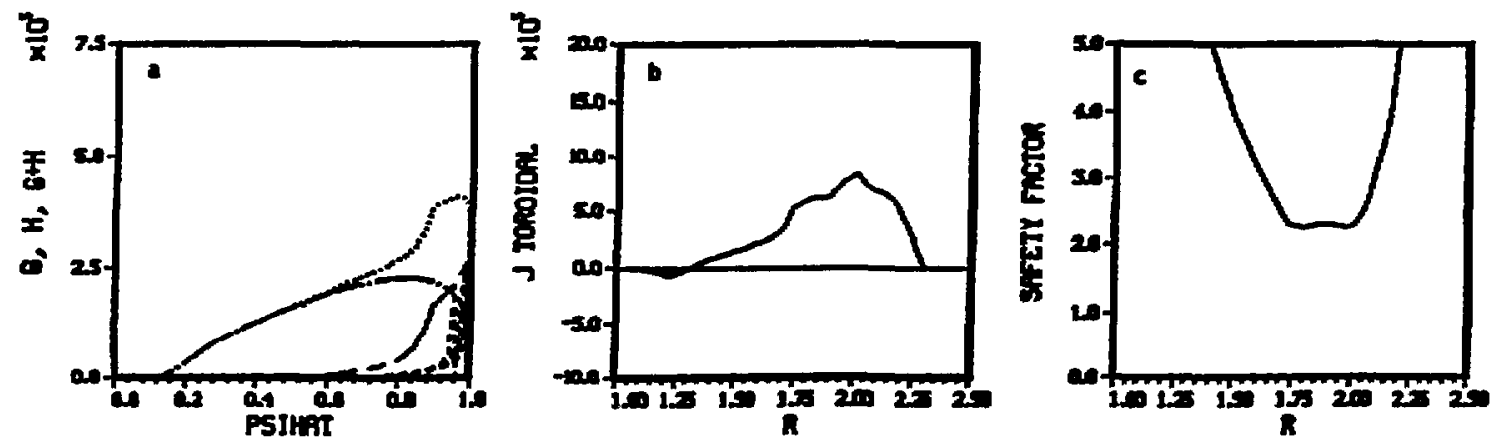

Figure 4. For case 53, the self-consistent wD equilibrium showing: a) the flux-surface-averaged bootstrap current density (chaindot), the wave driven seed current near the engnetic axis (PSIHAT $=1.0$ ), and the total current density (dotted), va. normalized poloidal flux; b) the resulting toroldal current density profile in the aldplane; c) the sarety ractor. 


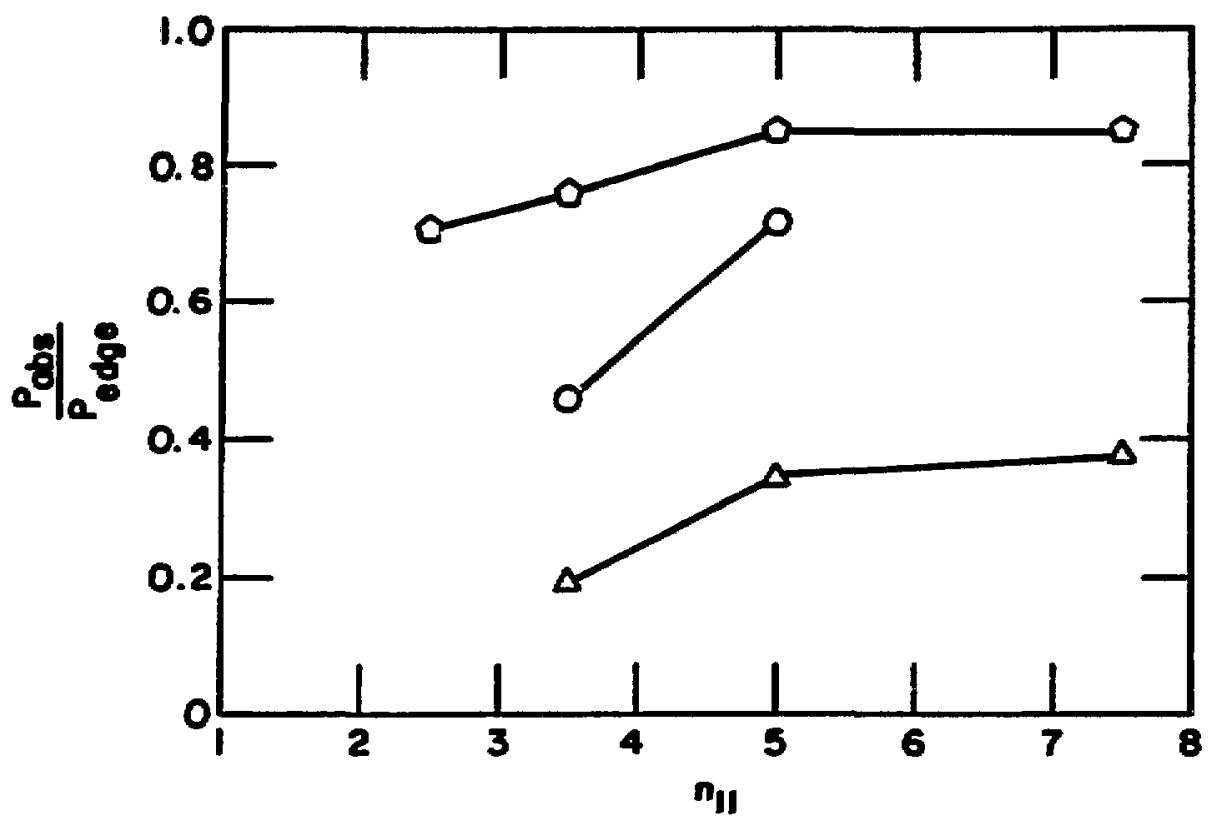

Figure 5. Single pass absorption vs. $n_{1}$. Top curve: $T_{e 0}=6.5 \mathrm{keV}, B_{0}=$ $1.0 \mathrm{~T}, B_{t}=1.0 \mathrm{~T}, B_{t}=2.2 \%$. Middle curve: $T_{e o}=3.5 \mathrm{keV}$, $B_{0}=1.0 \mathrm{~T}, B_{t}=1.28$. Botton curve: $T_{e 0}=6.5 \mathrm{keV}, B_{0}=$ $1.9 \mathrm{~T}, B_{\mathrm{t}}=0.78$.

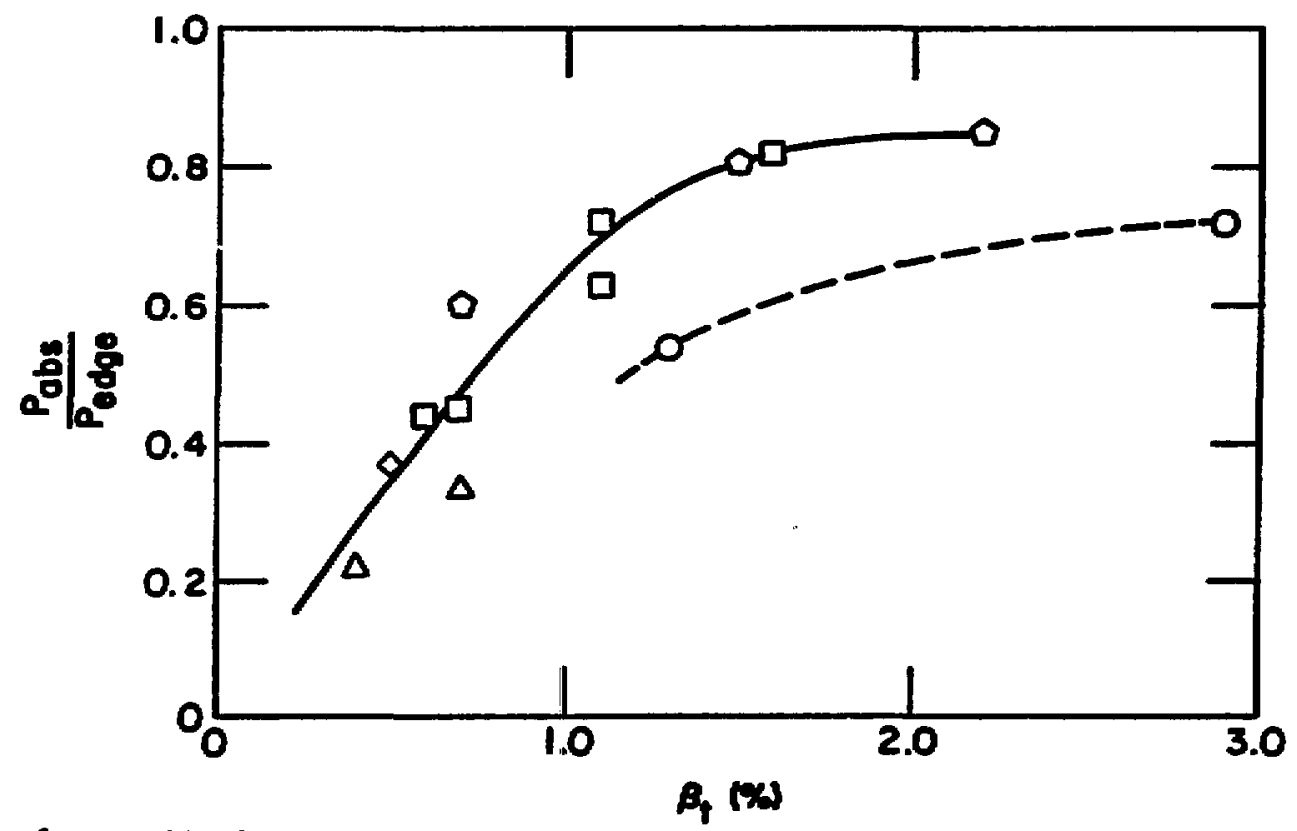

Figure 6. Single pass absorption vs. beta. Points clustered around upper curve have $n_{1}=5.0$; open clrcles are $n_{1}=2.5$. Results include both $T_{e O}=6.5 \mathrm{keV}$ and $3.5 \mathrm{keV}$ and $B_{0}=1.0 \mathrm{~T}$ and $1.9 \mathrm{~T}$. 

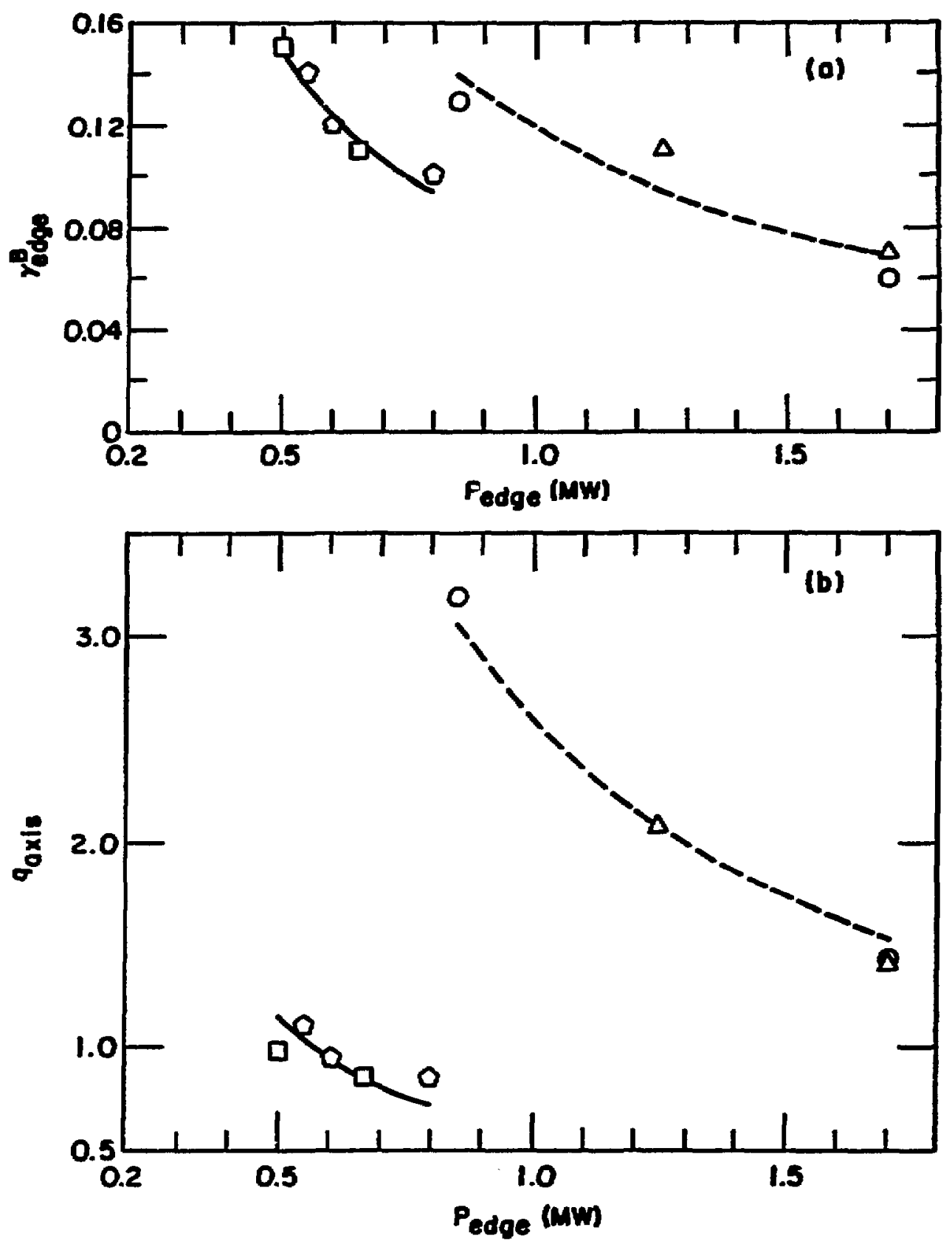

Figure 7. Influence of $P_{\text {edge on: a) }} \mathbf{r}_{\text {edge and }}$ b) axis safety factor. Dotted curves are low beta $(=0.75)$ with $T_{e}=1.5 \mathrm{keV}$ and 2.2 keV. Solid curves are higher beta (* 1.4-2.95) with $\mathrm{t}_{\mathrm{e}}=1.5 \mathrm{keV}$ and $2.8 \mathrm{keV}$. 

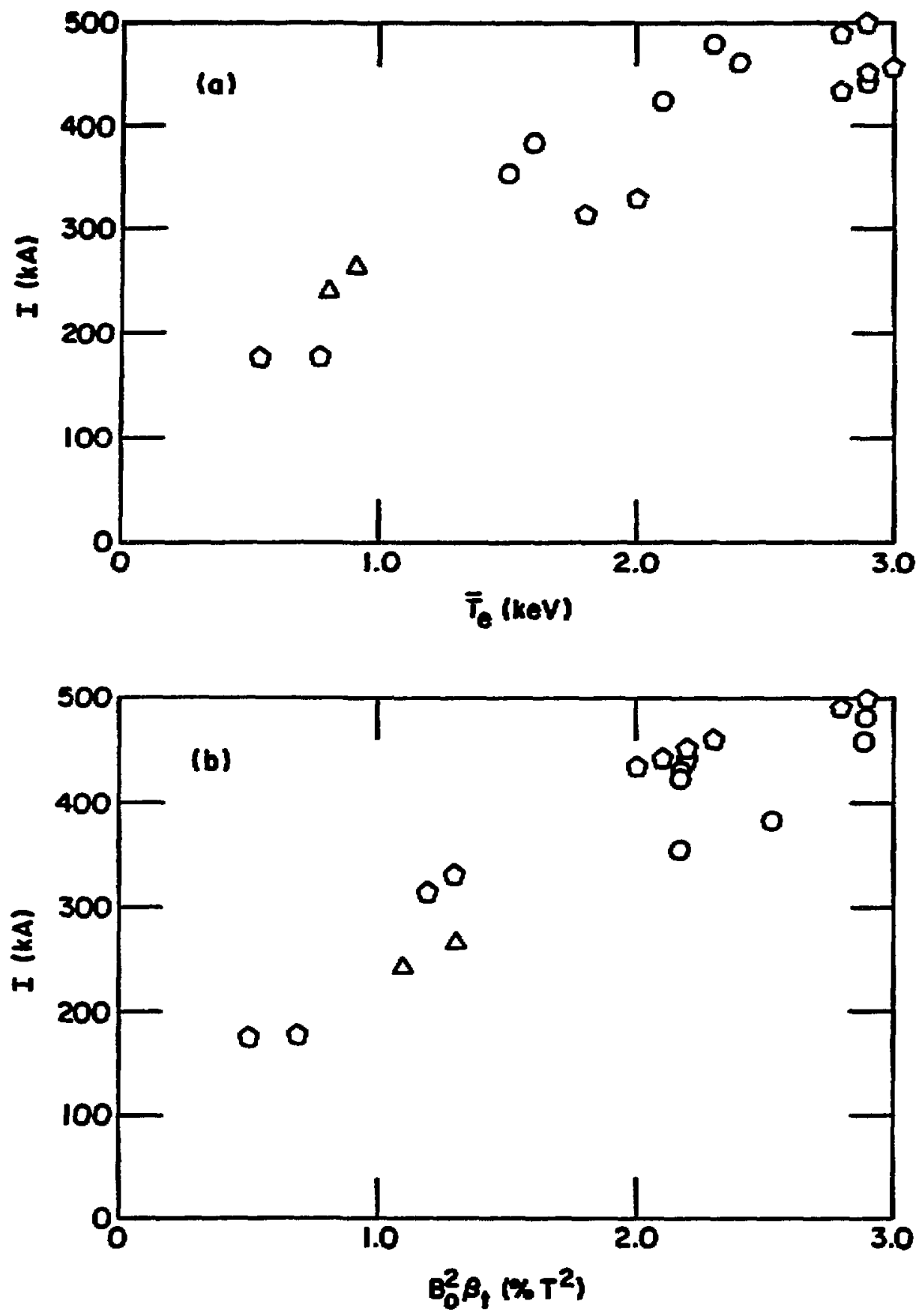

Figure 8. Total current vs. a) $\mathrm{T}_{e}$ and b) pressure; all with $\mathrm{z}_{\text {eff }}=2.2$. Pentagons have $\mathrm{T}_{e 0}=6.5 \mathrm{keV}, \mathrm{n}_{e 0}=0.18 \times 10^{20} \mathrm{~m}-3, \mathrm{~B}_{0}=1.0 \mathrm{~T}$, various $n_{1}$; open circles have $T_{e 0}=6.5 \mathrm{keV}, n_{e 0}=0.30 . x$ $10^{20} \mathrm{~m}^{-3}, \mathrm{~B}_{0}=1.9 \mathrm{~T}$, various $\mathrm{n}_{1}$; triangles have $\mathrm{T}_{\mathrm{eo}}=3.5 \mathrm{keV}$, $n_{e 0}=0.30 \times 10^{20}=-3, B_{0}=1.0 \mathrm{~T}$, different $n_{1}$. 


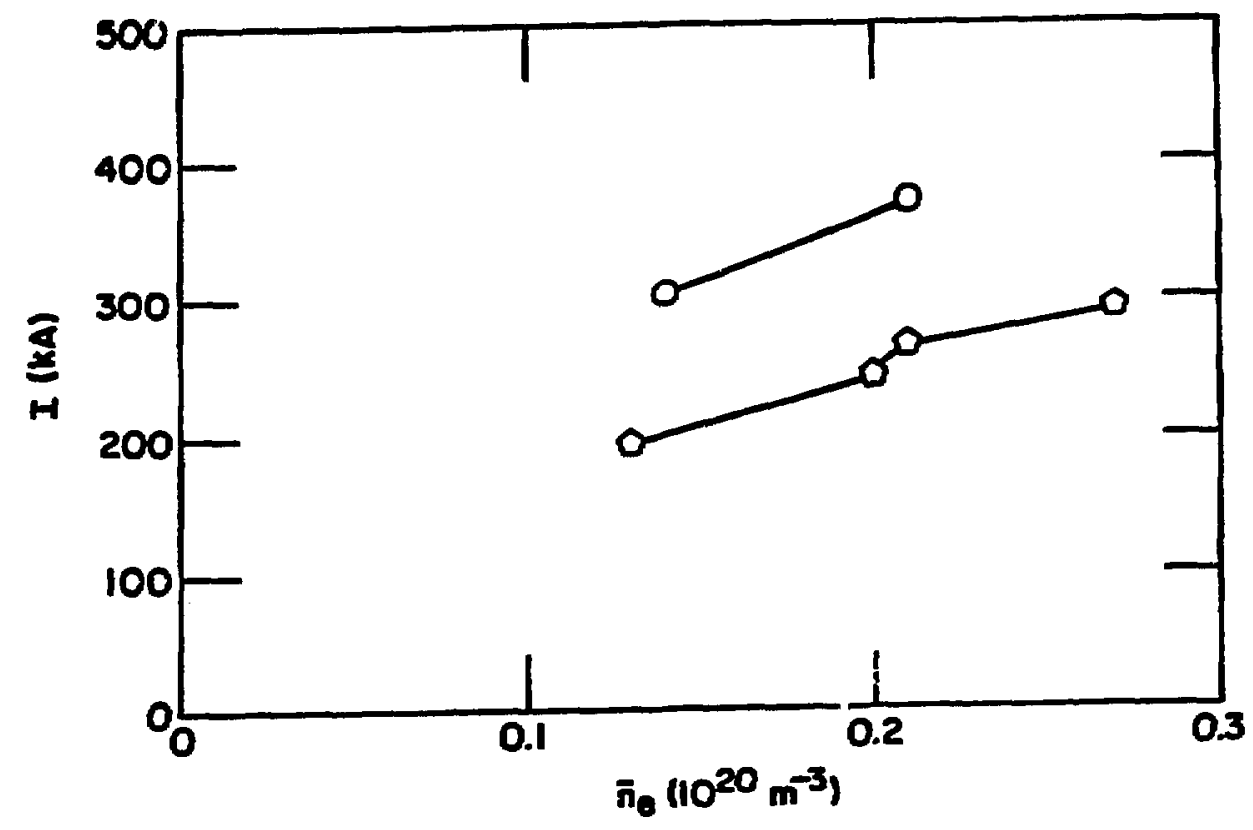

Figure 9. Current vs. average density. Top curve: $T_{e}=1.7 \mathrm{keV}, z_{\text {eff }}=$ 4.0, $B_{t} \leq 0.7 \%, P_{\text {edge }}=1.80 \mathrm{~m}$. Botton curve: $T_{e}=0.8 \mathrm{keV}$, $Z_{\text {eff }}=2.2, B_{t} \geq 0.7 \%, P_{\text {edge }}=1.10 \mathrm{kw}$.

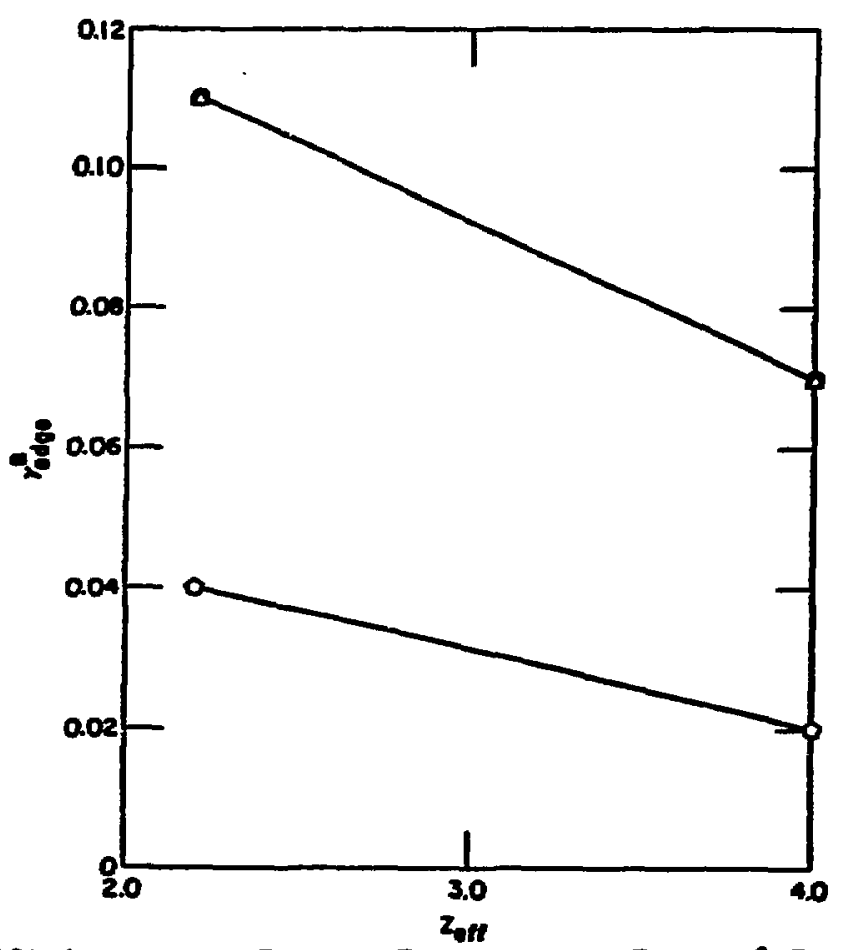

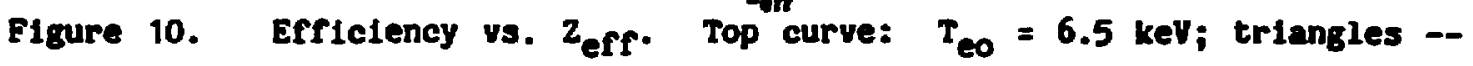
$B_{t}=1.4 \%$, circles $-s_{t}=0.7 \%$. Botton curve: $T_{e 0}=3.5 \mathrm{keV}$, $c_{t}=0.75$. 


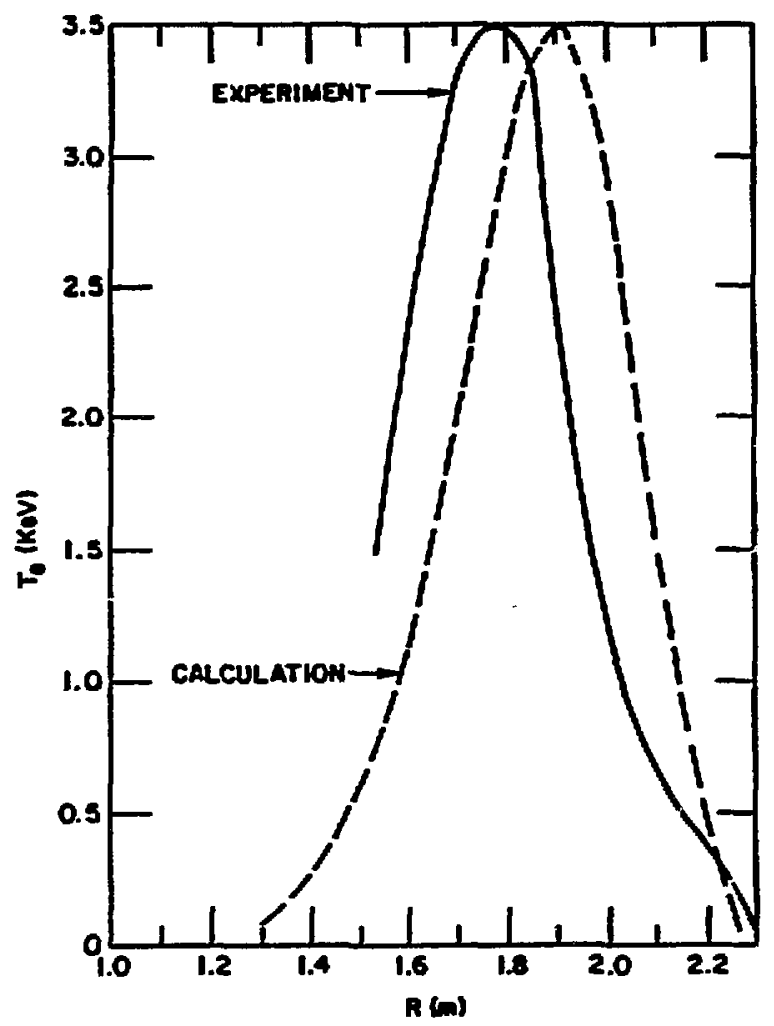

Figure 11. Temperature profile (dashed) obtained from FuCD calculation $\left(T_{e}=0.69 \mathrm{keV}, n_{e o}=0.20 \times 10^{20} \mathrm{~m}^{-3}, \bar{n}_{e}=0.13 \times 10^{20} \mathrm{~m}^{-3}\right.$, $\left.B_{0}=1 \mathrm{~T}, 2=4.0, P_{\text {edge }}=1.80 \mathrm{~m}, I_{0}=176 \mathrm{kA}\right) ;$ and temperature profile (solid) measured in DIIID [12].
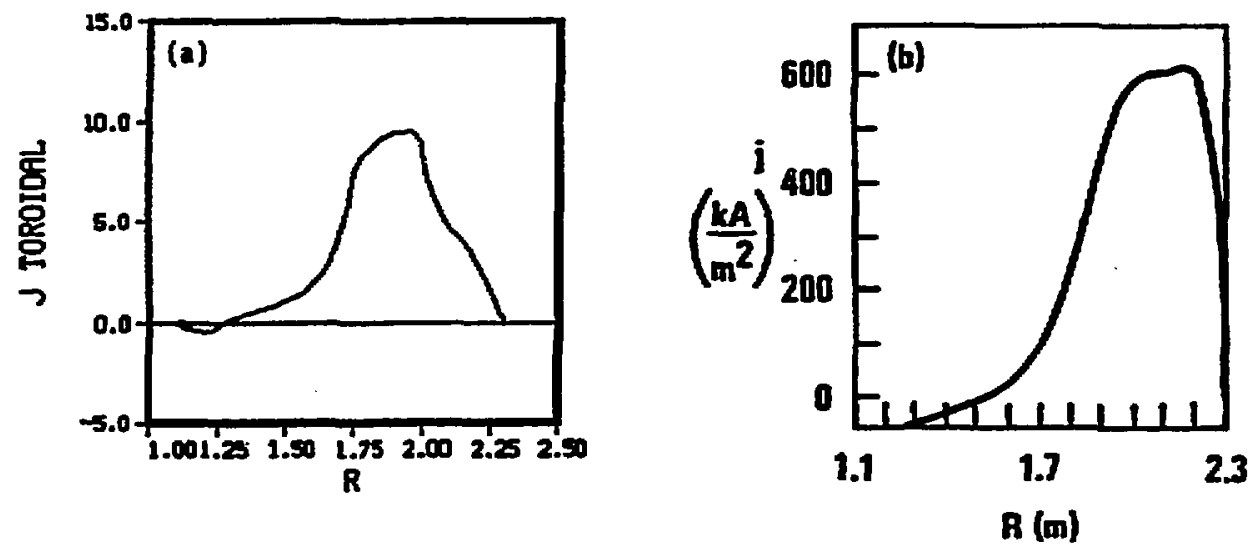

Figure 12. Calculated toroidal current density in midplane (a) with FuCD (296 kA); experimental current density (b) from NBCD [11] $(340 \mathrm{kA})$. 
Table 1: Typlcal Rasults for DIIIO fwco

\begin{tabular}{|c|c|c|c|c|c|c|c|c|c|c|}
\hline $\operatorname{cosen}$ & $\begin{array}{c}B_{0} / z_{\text {off }} \\
\text { (T) }\end{array}$ & $10^{20}{ }^{n}=3$ & ${ }_{k \in 0}^{T} T_{0}$ & "I & $P_{a b s} P_{\text {adge }}$ & $\begin{array}{l}10 \\
k A\end{array}$ & $\stackrel{8}{\gamma_{\text {odge }}}$ & $\begin{array}{c}B_{t} \\
8\end{array}$ & $9_{T}$ & Paxis \\
\hline 62 & $1.0 / 2.2$ & $.18 / .13$ & $6.5 / .77$ & 3.0 & $.21 / .35$ & 177 & .10 & 0.7 & 2.4 & .91 \\
\hline 10 & $1.0 / 2.2$ & $.18 / .07$ & $6.5 / 1.8$ & 2.5 & $.40 / .75$ & 313 & .05 & 1.2 & 2.2 & .66 \\
\hline 42 & $1.0 / 2.2$ & $.18 / .06$ & $6.5 / 2.0$ & 2.5 & $.27 / .50$ & 330 & .09 & 1.5 & 2.4 & .95 \\
\hline 37 & $1.0 / 2.2$ & $.18 / .10$ & $6.5 / 2.8$ & 2.5 & $.43 / .60$ & 433 & .12 & 2.0 & 2.8 & .95 \\
\hline 30 & $1.0 / 2.2$ & $.18 / .10$ & $6.5 / 2.9$ & 2.5 & $.39 / .55$ & 442 & .14 & 2.2 & 2.9 & 1.10 \\
\hline 41 & $1.0 / 2.2$ & $.18 / .10$ & $6.5 / 2.9$ & 3.5 & $.42 / .35$ & 442 & .14 & 2.1 & 2.9 & 1.07 \\
\hline 43 & $1.0 / 2.2$ & $.18 / .10$ & $6.3 / 2.9$ & 5.0 & .977 .55 & 452 & .14 & 2.2 & 2.9 & 1.20 \\
\hline 14 & $1.0 / 2.2$ & $.18 / .11$ & $6.5 /-3$ & 7.5 & $\sim .47 / .55$ & 459 & .14 & 2.3 & 3.0 & 1.43 \\
\hline 50 & $1.0 / 4.0$ & $.20 / .13$ & $6.5 / 1.4$ & 3.0 & $.76 / .98$ & 296 & .07 & 1.4 & 2.8 & .83 \\
\hline 30 & $1.0 / 4.0$ & $.20 / .13$ & $3.5 / .69$ & 3.0 & $.79 / 1.60$ & 176 & .02 & 0.6 & 2.2 & 1.05 \\
\hline 60 & $1.0 / 2.2$ & $.20 / .13$ & $3.5 / .74$ & 5.0 & $.54 / 1.20$ & 194 & .04 & 0.7 & 2.2 & 1.10 \\
\hline 63 & $1.0 / 2.2$ & $.30 / .20$ & $3.5 / .00$ & 3.0 & $.76 / 1.05$ & 242 & .00 & 1.1 & 2.6 & 1.17 \\
\hline 64 & $1.0 / 2.2$ & $.40 / .27$ & $3.3 / .86$ & 3.0 & $.6 / 7.05$ & 291 & .13 & 1.6 & 3.4 & 1.23 \\
\hline 65 & $1.9 / 2.2$ & $.40 / .28$ & $3.3 \% .93$ & 3.0 & $.73 / 2.00$ & 293 & .07 & 0,5 & 2.0 & 3.8 \\
\hline 47 & $1.9 / 2.2$ & $.30 / .13$ & $6.5 / 2.1$ & 3.0 & $.37 / 1.70$ & 424 & .06 & 0.6 & 1.7 & 1.44 \\
\hline 4 & $1.9 / 2.2$ & $.30 / .24$ & $6.5 / 2.4$ & 3.5 & $.32 / 1.70$ & 463 & .07 & 0.6 & 1.9 & 2.6 \\
\hline 33 & $1.0 / 4.0$ & $.30 / .21$ & $6.5 / 1.7$ & 3.0 & $.39 / 1.80$ & 370 & .07 & 0.7 & 2.1 & 2.20 \\
\hline 34 & $1.9 / 4.0$ & $.20 / .14$ & $6.5 / 1.7$ & 3.0 & $.30 / 1.00$ & 303 & .04 & 0.4 & 1.7 & 2.37 \\
\hline
\end{tabular}

